\title{
PENERAPAN TTG MESIN PENGADUK JELADREN DAN RISOPAN JUMBREK DI IKM PACIRAN LAMONGAN
}

\author{
Muhaji \\ Jurusan Teknik Mesin Fakultas Teknik Universitas Negeri Surabaya \\ Email: muhaji61@unesa.ac.id
}

\begin{abstract}
Abstrak - Tujuan dari kegiatan ini dalah (1) merancang, membuat dan menerapkan mesin pengaduk jeladren dan risopan jumbrek, (2) untuk meningkatan produktivitas dan higine kue jumbrek. Berdasarkan pengkajian dan observasi yang dilakukan di UKM mitra, UKM dibuatkan mesin pengaduk jeladren dari dengan bahan stinless stell dengan pengerak motor listrik. Begitu juga dengan risopan terbuat dari plat stainless steel. Hasil kegiatan PKM menunjukkan bahwa mesin pengaduk jeladren jumbrek dan alat pengukus jumbrek secara fisik kunstruksi mesin dan alat sangat baik, kokoh, praktis. Hasil uji coba mesin pengaduk jeladren jumbrek menunjukkan bawa sekali pengadukan sebanyak $10 \mathrm{~kg}$ dengan waktu rata-rata 12,5 menit, sehingga untuk mengaduk bahan $40 \mathrm{~kg}$ diperlukan waktu 50 menit. Sedangkan pengadukan dengan tenaga manusia untuk mengaduk $40 \mathrm{~kg}$ bahan (diperlukan 8 kali pengadukan dalam waktu 200 menit), dengan demikian waktu pengadukan 4 kali lebih cepat. Hasil uji coba risopan jumbrek menunjukkan bawa dalam waktu 30 menit mampu memproduksi (mengukus) 140 biji jumbrek. Peningkatan hasil dari pengukus lama dengan pengukus baru 5 kali lipat.
\end{abstract}

Kata kunci: teknologi tepat guna, jumbrek, mesin pengaduk, risopan

\begin{abstract}
The purpose of this activity was designed, (1) make and apply a mixer jeladren machine and risopan jumbrek, (2) to improving productivity and jumbrek higine cake. Based on studies conducted in smes and observation, partner smes make jeladren mixer machine with a stinless stell with an electric motor. So are risopan made of plate stainless steel. The outcome of the activities PKM shows that machine mixer jeladren jumbrek and risopan jumbrek physically cunstruction machines and instrument very good, stout, practical. The results of the tryouts machine jeladren mixer jumbrek pointed out once mixer as $10 \mathrm{~kg}$ with 12,5 minutes the average time, so as to mixer material 40 pouns needed time 50 minutes. While with human resources for mixer 40 pounds of (necessary 8 times mixer in the 200 minutes), thus time mixer 4 times faster. The results of the tryouts risopan jumbrek pointed out in time capable of producing 140 seeds jumbrek/30 minutes. Increase the result of long with new risopan 5 times.
\end{abstract}

Keywords: effective technology, jumbrek, mixer machine, risopan

\section{PENDAHULUAN}

Wilayah pesisir pantai utara (pantura) Kecamatan Paciran menjadi "kiblat" wisata Lamongan. Selain tempattempat wisata modern (wisata baharí lamongan) dan wisata religi (makam Sunan Drajat), daerah yang udaranya terik ini juga memberikan suguhan wisata kuliner. Salah satu kuliner khasnya yang unik dan enak adalah kue jumbrek.

Terdengar aneh ketika pertama kali mendengar kata jumbrek, tapi ketika sudah mencicipi rasanya tidak akan terlupakan. Rasa dan bentuknya mempunyai sensasi tersendiri dan mudah menggoda orang. Jumbrek terbuat dari campuran tepung beras, santan, dan sirup gula siwalan [1]. Proses pembuatannya dimulai dengan mencampur tepung beras dengan santan sampai tercampur rata dan homogen, proses pengadukan ini memerlukan waktu kurang lebih 30 menit, tergantung jumlah bahannya. Pada saat yang sama, sirup gula siwalan direbus dengan sedikit air di dalam tungku kayu bakar selama 1 jam sampai diperoleh sirup gula yang kental. Sirup gula siwalan kemudian dituangkan pada adonan tepung beras dan santan yang sudah tercampur tadi, lalu ditambah sedikit tepung tapioka untuk menambah tekstur kenyal, kemudian semua adonan diaduk hingga rata. Adonan ini kemudian dituang ke dalam daun lontar (siwalan) yang telah dibentuk menjadi kerucut, menyerupai terompet kecil, panjangnya kira-kira $25 \mathrm{~cm}$. Jika "terompet" daun lontar tadi tidak dibuat dengan benar, maka adonan ini akan bocor [1].

Jumbrek memiliki daya simpan relatif pendek, yakni 2-3 hari. Kerusakan utama yang sering dijumpai adalah terjadinya sineresis, yaitu keluarnya air dari gel pati sehingga menyebabkan permukaan jumbrek menjadi basah dan akhirnya air tersebut keluar dari pengemas merembes keluar. Selain itu terjadinya retrogradasi pada jumbrek yang ditandai dengan mengerasnya permukaan luar jumbrek sehingga menyebabkan konsumen kurang menyukai [2].

Permasalahan tersebut banyak dialami oleh para pembuat (industri kecil) jumbrek yang ada di desa Paciran kecamatan Paciran yang merupakan sentra pembuat dan 
penjual berbagai jajanan khas Lamongan. Di sepanjang jalan Deandels Paciran ada \pm 50 pembuat atau industri kecil jumbrek. Bu Karmini dan Sri Rejeki adalah kedua pengusaha jumbrek atau industri kecil jumbrek yang mengalami permasalah tersebut. Setiap hari Bu Karmini dan Sri Rejeki harus menyediakan \pm 1600 bj jumbrek. Untuk membuat jumbrek sebanyak itu dibutuhkan $40 \mathrm{~kg}$ tepung beras dan 50 bj kelapa untuk santan kental dan 5 liter sirup gula siwalan. Bahan tersebut dibagi menjadi 8 kali pembuatan adonan, setiap kali pembuatan adonan diperlukan $5 \mathrm{~kg}$ tepung beras dan 10 butir kelapa dengan waktu 25 menit, hasil jadi setiap kali adonan sebanyak \pm 200 bj jumbrek. Sehingga setiap hari harus membuat 8 kali pembuatan adonan jumbrek. Pembuatan adonan jumbrek selama ini dilakukan oleh tenaga manusia, sehingga dibutuhkan tenaga yang kuat dan konstan selama pengadukan agar jeladren bisa tercampur rata dan tidak berbutir. Tetapi seringkali karena keterbatasan tenaga yang sudah lelah, maka hasil adonan jumbrek tidak bisa rata dan berbutir, sehingga tekstur jumbrek tidak halus yang akan mempengaruhi rasa jumbrek, sehingga produktivitasnya tidak bisa maksimum. Hal ini sesuai dengan penjelasan [3] bahwa industri kecil di berbagai wilayah Jawa Timur kondisinya masih sangat membutuhkan adanya pembinaan yang intensif, terutama untuk meningkatkan produktivitasnya.

Berkaitan dengan produktivitas industri [4] mengatakan bahwa suatu industri baru bisa dikatakan produktif jika industri tersebut dapat dilaksanakan secara efisien dan efektif, atau dapat menggunakan sumber daya yang seminimal mungkin dengan hasil yang seakurat mungkin. Menurut [5] ada beberapa cara yang dapat ditempuh oleh pengusaha kecil untuk meningkatkan efisiensi dan efektivitas usahanya, antara lain: 1) dengan meningkatkan skill atau keterampilan karyawannya, dan 2) dengan memutakhirkan peralatan produksinya. Lain halnya dengan cara yang biasa ditempuh oleh pengusaha-pengusaha yang sudah besar (profesional), mereka rata-rata lebih suka memilih cara untuk memutakhirkan peralatan produksinya guna meningkatkan efisiensi dan efektifitas usahanya [6].

Selanjutnya [7] menyatakan bahwa pada umumnya masalah produksi yang dihadapi oleh industri kecil dan menengah di Indonesia tidak cocok bila dipecahkan melalui penerapan/penggunaan mesin-mesin yang berteknologi mutakhir/canggih, tetapi justru banyak yang lebih cocok dipecahkan melalui penerapan teknologi tepat guna (TTG). Sebab biaya investasi untuk penerapan TTG relatif murah dan umumnya dapat terjangkau. Disamping itu pengoperasian dan perawatannya tidak membutuhkan penguasaan ilmu pengetahuan dan pengetahuan teknologi yang terlalu tinggi.

Permasalahan yang dialami oleh industri kecil jumbrek tersebut perlu dicarikan alternatif pemecahannya, agar kualitas jumbrek sebagai jajanan khas tradisional Lamongan tetap bisa bertahan. Alternatif pemecahan yang bisa dilakukan adalah dengan dibuatkan alat yang bisa menggantikan tenaga manusia dalam mengaduk adonan jumbrek dengan alat mesin pengaduk adonan yang digerakkan oleh motor listrik yang mempunyai tenaga besar dan konstan, sehingga adonan bisa rata dan homogen serta tidak berbutir. Permasalahan lain adalah alat pengukusnya, selama ini untuk mengukus jumbrek masih tradisional yaitu dengan menggunakan dandang senggah dan dandang sabruk yang memakai kukusan yang terbuat dari pohon bambu. Kelemahan alat ini adalah ketika dipanasi uap yang ada di dalam dandang banyak yang keluar, karena antara kukusan dengan penutupnya (kekep) tidak rapat, sehingga pengukusannya memerlukan waktu yang relatif lama. Oleh karena itu, merupakan tindakan yang tepat dan solutif sekali bila kegiatan PKM ini berusaha merancang dan mewujudkan (TTG) untuk membantu mengatasi permasalahan yang dihadapi IKM untuk meningkatkan produktivitasnya.

\section{Metode}

\section{METODE}

Metode yang digunakan dalam Pengabdian Kepada Masyarakat (PKM) ini adalah dengan melakukan rancang bangun Teknologi Tepat Guna (TTG) Mesin Pengaduk jeladren jumbrek dan Risopan (alat pengukus) jumbrek untuk menggantikan fungsi alat yang selama ini digunakan industri kecil mitra (IKM).

\section{Teknik Merancang}

Secara berturut-turut perancangan TTG ini diawali dengan membuat gambar kerja mesin pengaduk jeladren dan resopan seperti gambar 1, 2 dan 3. Langkah selanjutnya adalah pembuatan TTG sesuai dengan hasil rancangan, kemudian diujicoba dan dianalisis, serta dilakukan perbaikan sesuai dengan unjuk kerja TTG yang diinginkan.

\section{Rancangan Mesin Pengaduk Jeladren Jumbrek}

Rancangan mesin pengaduk jeladren jumbrek dan spesifikasinya seperti ditunjukkan pada gambar 1 dan 2 .

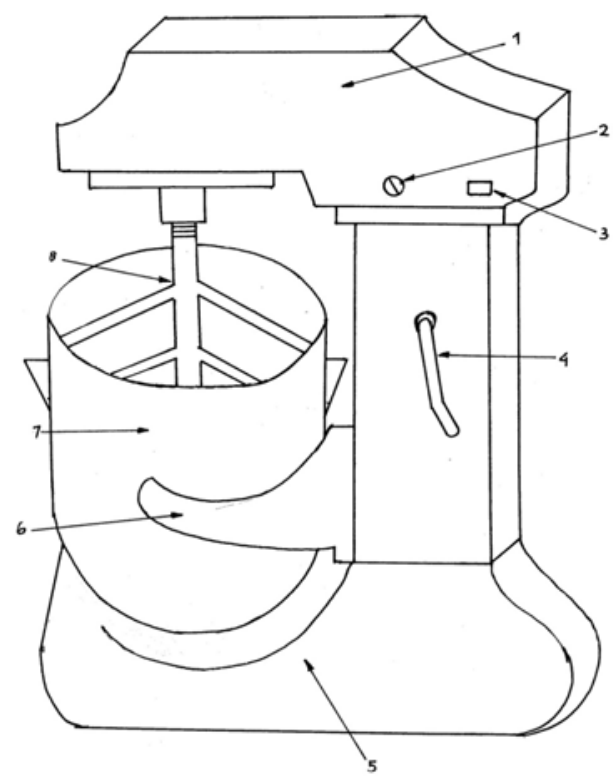

Gambar 1. Rancangan Mesin Pengaduk Jeladren Jumbrek 
Keterangan gambar:

1. Rumah motor listrik, gigi penggerak, gigi yang digerakkan dan sambungan pengaduk

2. Tombol pengatur putaran motor

3. Tombol on/of

4. Pengatur tinggi rendahnya baskom

5. Dudukan baskom

6. Pemegang baskom

7. Baskom tempat adonan

8. Pengaduk adonan

Sedangkan rancangan gambar motor listrik, gigi penggerak, gigi yang digerakkan, pengaduk adonan, dan baskom ditunjukkan seperti pada gambar 2 berikut:

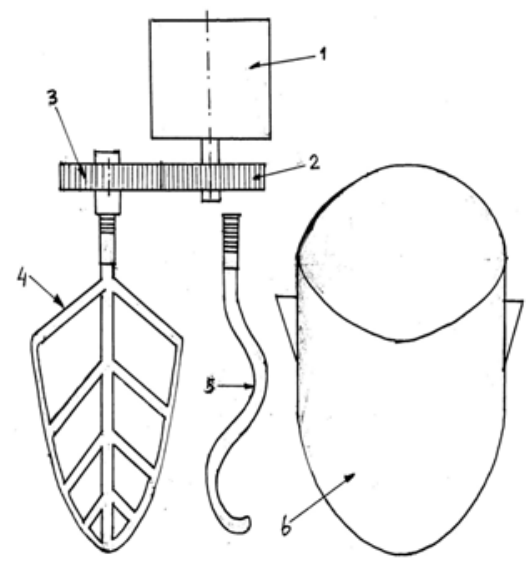

Gambar 2 Rancangan Komponen Mesin Pengaduk Jeladren Jumbrek

Keterangan gambar 2:

1. Motor listrik

2. Roda gigi penggerak

3. Roda gigi yang digerakkan

4. Pengaduk adonan kering dan basah

5. Pengaduk adonan kenyal

6. Baskom tempat adonan

Spesifikasi mesin pencampur bahan dan komponennya adalah sebagai berikut:

- Kapasitas mesin pencampur adonan 10 kg (5 x lebih banyak dibandingkan dengan pencampur tradisional /tenaga manusia)

- Kerangka terbuat dari profil U

- Dinding terbuat plat besi

- Daya motor listrik 2 PK

- Pengaduk terbuat dari steinless stell

- Baskom terbuat dari plat steinless stell

- Roda penggerak gigi terbuat dari baja

\section{Rancangan Risopan (Pengukus) Jumbrek}

Rancangan risopan dan spesifikasinya yang akan diterapkan pada industri mitra seperti gambar 3 .

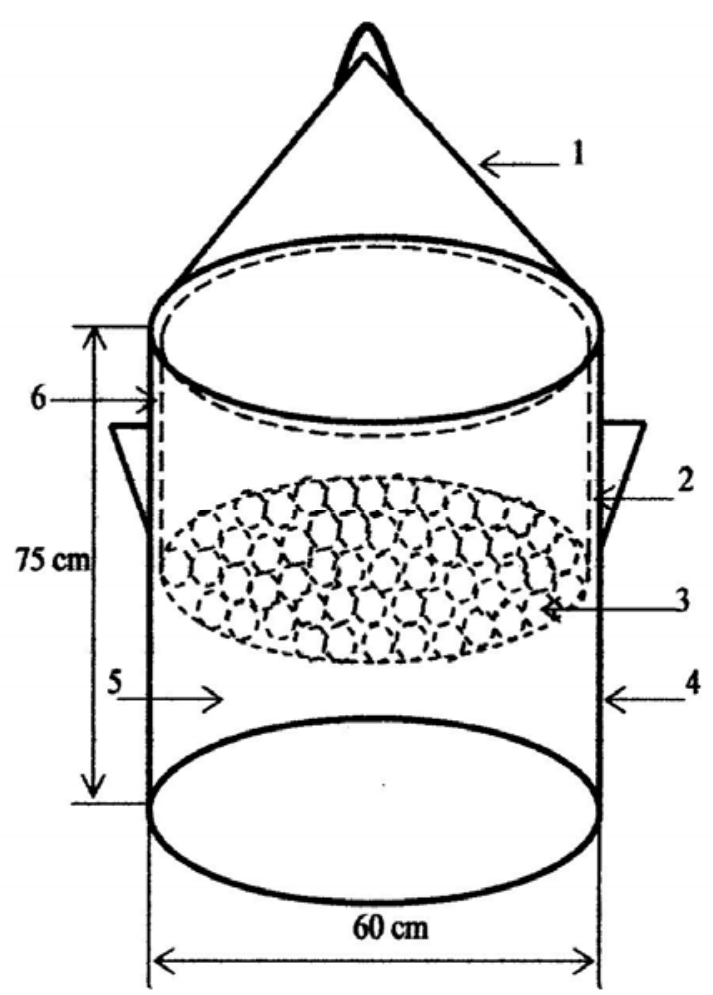

Gambar 3. Rancangan Risopan Jumbrek

Keterangan gambar 3:

1. Tutup risopan

2. Bodi sarangan tempat jumbrek dikukus

3. Lobang tempat dudukan jumbrek

4. Bodi risopan

5. Tempat air kukus

6. Bodi sarangan jumbrek

7. Lubang saluran uap

Kapasitas dan spesifikasi Risopan:

- Kapasitas risopan 140 biji ( 3 x lebih banyak dibandingkan pengukus dengan dandang senggah)

- Bodi risopan terbuat dari plat stenless stell, tinggi $75 \mathrm{~cm}$ dan diameter $50 \mathrm{~cm}$

- Sarangan terbuat dari plat steinless stell, dengan diameter lubang tempat jumbrek $2 \mathrm{~cm}$, lubang sirkulasi uap $0,5 \mathrm{~cm}$

\section{HASIL DAN DISKUSI}

\section{A. Hasil Rancang Bangun}

1. Hasil Rancang Bangun Mesin Pengaduk Jeladren dan Risopan Jumbrek

Hasil rancangan mesin pengaduk jeladren dan risopon (alat pengukus) jumbrek ditunjukkan pada gambar 4 dan 5 . 


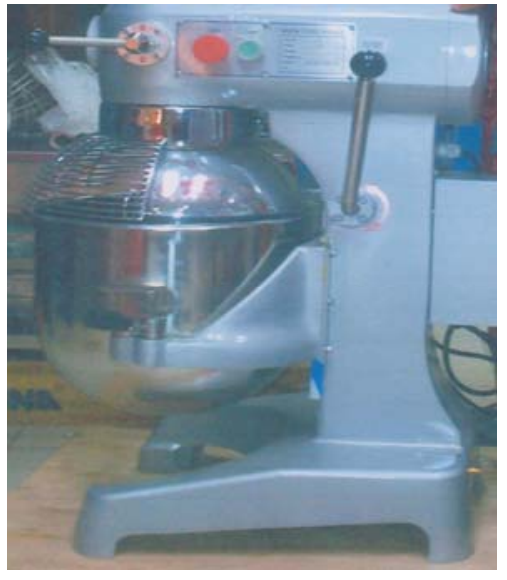

Gambar 4. Mesin Pengaduk Jeladren Jumbrek
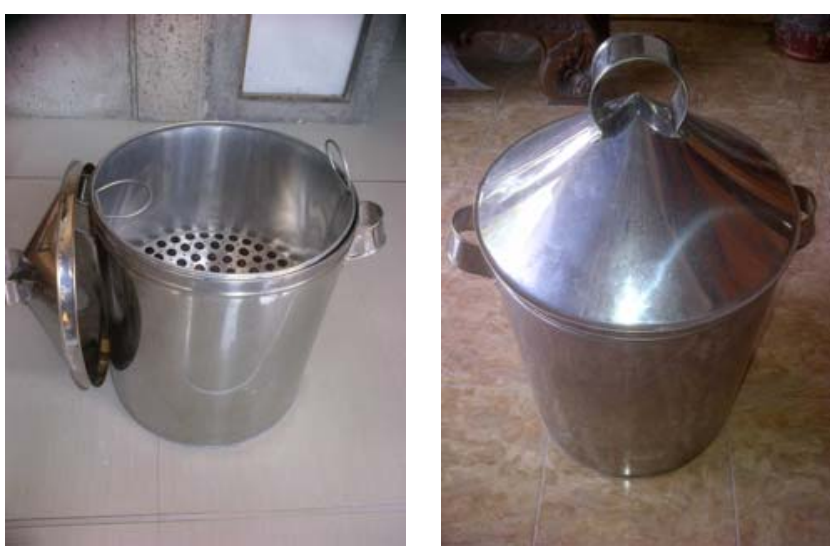

Gambar 5. Risopan Jumbrek

B. Hasil Uji Coba Mesin Pengaduk Jeladren dan Alat Pengukus Jumbrek

1. Hasil Uji Coba Mesin Pengaduk Jeladren

Hasil uji coba mesin pengaduk jeladren jumbrek seperti ditunjukkan pada gambar 6, tabel 1 dan gambar 7 .

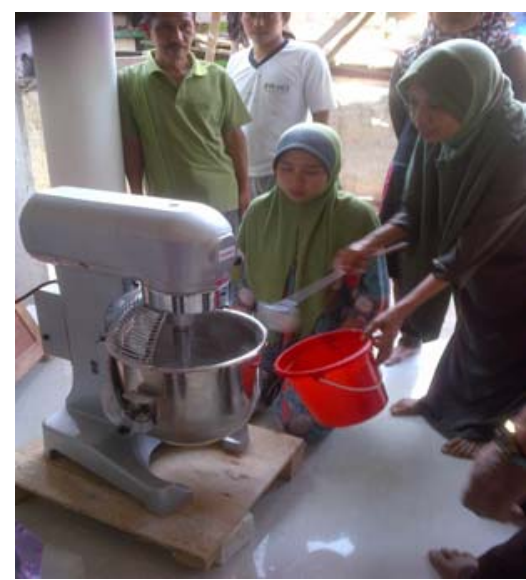

Gambar 6. Uji coba mesin pengaduk jeladren
TABEL 1: HASIL UJI COBA MESIN PENGADUK JELADREN JUMBREK

\begin{tabular}{|c|c|c|c|c|}
\hline No. & $\begin{array}{c}\text { Putaran } \\
\text { mesin } \\
(\mathrm{rpm})\end{array}$ & $\begin{array}{c}\text { Putaran } \\
\text { gerbox } \\
(\mathrm{rpm})\end{array}$ & $\begin{array}{c}\text { Kapasitas } \\
\text { jeladren } \\
(\mathrm{kg})\end{array}$ & $\begin{array}{c}\text { Lama waktu } \\
\text { pengadukan } \\
(\text { menit })\end{array}$ \\
\hline 1 & 1000 & 15 & 10 & 20 \\
\hline 2 & 1200 & 20 & 10 & 15 \\
\hline 3 & 1400 & 25 & 10 & 10 \\
\hline 4 & 1600 & 30 & 10 & 5 \\
\hline
\end{tabular}

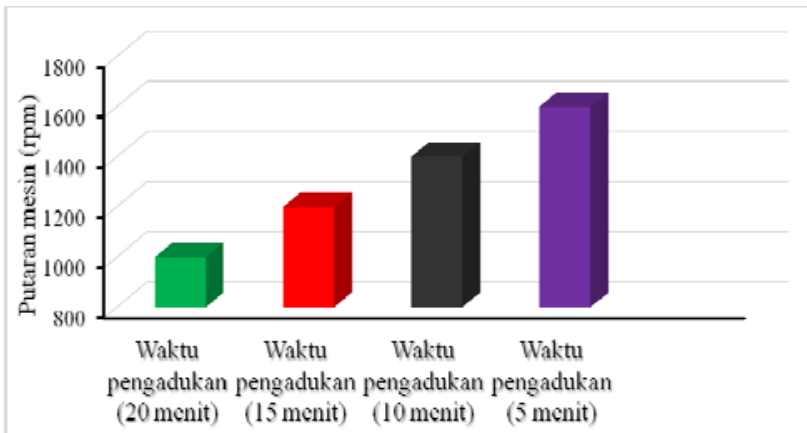

Gambar 7. Uji coba mesin pengaduk jeladren jumbrek

2. Hasil UJi Coba Risopan Jumbrek

Hasil uji coba risopan jumbrek seperti ditunjukkan pada gambar 8, tabel 1 dan gambar 9 .

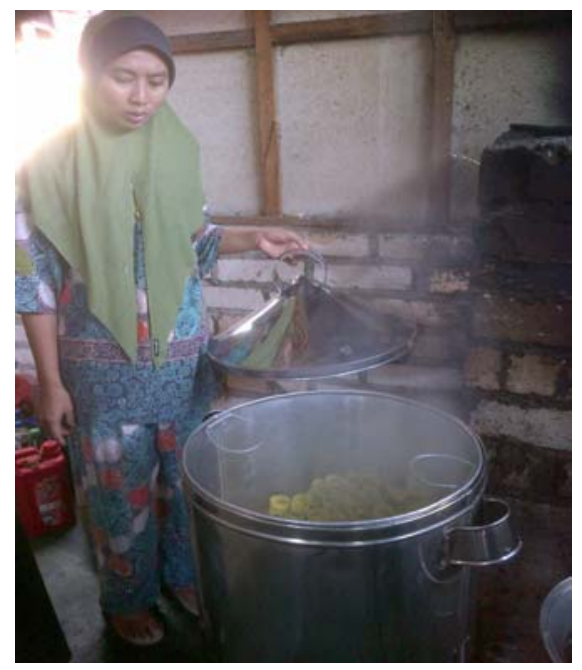

Gambar 8. Uji coba risopan jumbrek

TABEL 2: HASIL UJI COBA RISOPAN JUMBREK

\begin{tabular}{|c|l|c|c|}
\hline No. & \multicolumn{1}{|c|}{ Jenis Alat } & $\begin{array}{c}\text { Volume } \\
\text { jumbrek } \\
\text { (biji) }\end{array}$ & $\begin{array}{c}\text { Lama } \\
\text { pengukusan } \\
\text { (menit) }\end{array}$ \\
\hline 1. & Dandang aluminium & 40 & 75 \\
\hline 2. & Dandang tembaga & 50 & 60 \\
\hline 3. & Risopan steinless stell & 140 & 30 \\
\hline
\end{tabular}




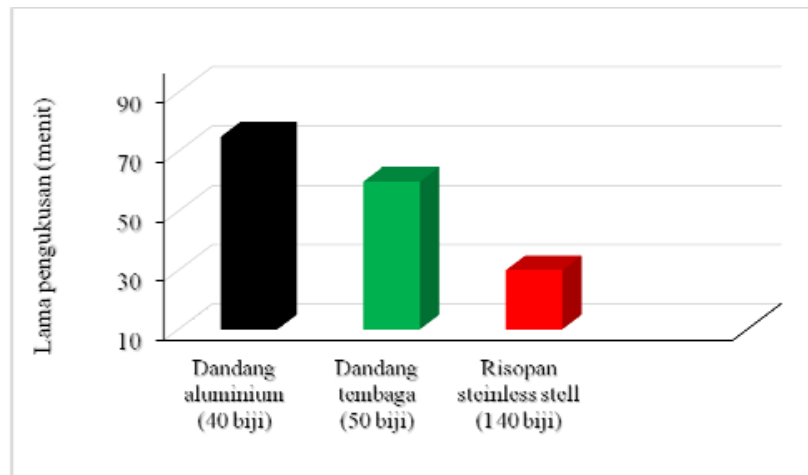

Gambar 9. Diagram batang pengaruh jenis alat pengukus, terhadap volume dan lama pengukusan jeladren

\section{B. Pembahasan}

Hasil analisis dari mesin pengaduk jeladren jumbrek menujukkan bahwa secara fisik kunstruksinya sangat baik, kokoh, praktis dan sesuai dengan harapan antara pelaksana dan mitra IKM untuk mengatasi kendala yang ada pada industri mitra IKM seperti yang ditunjukkan pada gambar 4 dan 5 .

Sedangkan dari hasil uji coba mesin pengaduk jeladren dengan kapasitas $10 \mathrm{~kg}$ seperti yang ditunjukkan pada tabel 1 dan gambar 7 menujukkan bawa dengan putaran mesin 1000rpm waktu pengadukan jeladren selama 20 menit, untuk putaran $1200 \mathrm{rpm}$ waktu pengadukan jeladren selama 15 menit, putaran 1400 rpm waktu pengadukan jeladren selama 10 menit dan putaran 1600 rpm waktu pengadukan jeladren selama 5 menit.

Dari hasil uji coba pengadukan jeladren dengan alat penggerak mesin waktu pengadukan empat kali lebih cepat dibanding dengan pengadukan menggunakan tenaga penggerak manusia. Sedangkan hasil jadi dari jumbrek sangat baik, campurannya lebih homogen dan jika dikunyah lebih lembut. Hal ini disebabkan karena pengadukan jeladren dengan tenaga penggerak mesin campurannya antara santan, gula, garam dan tepung berasnya bisa lebih homogen jika dibandingkan dengan menggunakan penggerak tenaga manusia, sehingga rasa jumbreknya menjadi lebih lezat. Produksinya menjadi meningkat tiga-empat kalinya jika dibandingkan dengan menggunakan pengaduk tenaga manusia, karena dengan menggunakan tenaga penggerak mesin sekali adonan bisa $10 \mathrm{~kg}$ dengan waktu sangat cepat, sedangkan menggunakan pengaduk tenaga manusia sekali jeladren hanya $5 \mathrm{~kg}$ dan waktunya sangat lama yaitu sampai 25 menit.

Hasil sangat meningkat sangat jauh sekali baik dalam kualitas maupun waktu pengukusan jika dibandingkan dengan alat pengukus yang lama yaitu menggunakan dandang senggah atau dandang sabruk yang memakai kukusan yang terbuat dari pohon bambu. Kelemahan alat ini adalah ketika dipanasi uap yang ada di dalam dandang banyak yang keluar, karena antara kukusan dengan penutupnya (kekep) tidak rapat, sehingga pengukusannya memerlukan waktu yang relatif lama. Jika menggunakan alat yang lama (dandang aluminium) memerlukan waktu 75 menit dengan daya tampung alat 40 biji jumbrek, (dandang tembaga) memerlukan waktu 60 menit dengan daya tampung alat 50 biji, sedangkan dengan risopan dari steinless stell mampu menampung 140 biji jumbrek dengan waktu 30 menit. Selama ini IKM sering menggunakan pengukus dandang senggah prosesnya 50 biji/60 menit, dan proses pengukus yang baru 280 biji/60 menit, sehingga peningkatannya adalah 5 kali lipat.

\section{KESIMPULAN}

Dari kegiatan PKM yang telah dilaksanakan oleh pelaksana dengan mitra IKM dapat disimpulkan sebagai berikut:

1. Mesin pengaduk jeladren jumbrek dan risopan (alat pengukus) jumbrek secara fisik kunstruksi alat yang dihasilkan sangat baik, kokoh, praktis dan sesuai dengan harapan antara pelaksana tim PKM dan mitra IKM.

2. Hasil uji coba mesin pengaduk jeladren jumbrek menunjukkan bawa sekali pengadukan sebanyak $10 \mathrm{~kg}$ dengan waktu rata-rata 12,5 menit. Waktu pengadukan 4 kali lipat.

3. Hasil uji coba risopan jumbrek menunjukkan bawa dalam waktu 30 menit mampu memproduksi (mengukus) 140 biji jumbrek. Peningkatan hasil dari pengukus lama dengan pengukus baru 5 kali lipat.

\section{REFERENSI}

[1] Taufiq, M. , Usaha Perbaikan Teknologi Pembuatan Jumbrek. Fakultas Pertanian Universitas Widya gama. Malang, 1997.

[2] Wahono, T., Studi Penentuan Deskriptor Mutu Sensoris Kue Jumbrek. Buletin habitat. Teknologi Pertanian Universitas Brawijaya. Malang Vol. VIII. No. 1000. Jal ; 420-423, 1997.

[3] Sutiono, Produktivitas UKM di Jawa Timur. Makalah yang disampaikan dalam rangka pelatihan produktivitas usaha kecil di Unesa.Tanggal 26 Juli tahun, 2001.

[4] Nyoman Sutantra I, Produktivitas Sistem Produksi dan dan Teknologi. Makalah yang disampaikan dalam rangka pelatihan produktivitas usaha kecil di Unesa.Tanggal 26 Juli tahun 2001.

[5] Haryono dkk., Buku Panduan Materi Kuliah Kewirausahaan. Unipres UNESA Surabaya, 1999.

[6] John E Biegel (1998). Pengendalian Produksi, Suatu Pendekatan Kuantitatif. Terjemahan. Tarsito Bandung

[7] Ahmadi Fuad, Karakteristik Teknologi Tepat Guna Dalam Industri Skala Usaha Kecil dan Menengah di Jawa Timur. Makalah yang Disampaikan dalam rangka pelatihan produktivitas usaha kecil diUnesa. Tanggal 26 Juli tahun 2001. 